\title{
Long-term use of lithium and risk of colorectal adenocarcinoma: a nationwide case-control study
}

\author{
Anton Pottegård ${ }^{\star}, 1$, Zandra Nymand Ennis ${ }^{2}$, Jesper Hallas ${ }^{1,2}$, Boye L Jensen ${ }^{3}$, Kirsten Madsen ${ }^{3,4}$ \\ and Søren Friis ${ }^{5}$ \\ ${ }^{1}$ Clinical Pharmacology, Department of Public Health, University of Southern Denmark, DK-5000 Odense, Denmark; ${ }^{2}$ Department \\ of Clinical Biochemistry and Pharmacology, Odense University Hospital, DK-5000 Odense, Denmark; ${ }^{3}$ Department of \\ Cardiovascular and Renal Research, University of Southern Denmark, DK-5000 Odense, Denmark; ${ }^{4}$ Department of Pathology, \\ Odense University Hospital, DK-5000 Odense, Denmark and ${ }^{5}$ Danish Cancer Society Research Center, Danish Cancer Society, \\ DK-2100 Copenhagen, Denmark
}

Background: Lithium accumulates in the colon and inhibits the enzyme GSK-3 $\beta$ that possesses anti-carcinogenic effects. We therefore examined the association between lithium use and colorectal cancer risk in a nationwide study.

Methods: We used the Danish Cancer Registry to identify all patients diagnosed with incident colorectal adenocarcinoma during 2000-2012 ( $n=36248$ ). Using a matched case-control approach, we estimated the association between long-term use ( $\geqslant 5$ years) of lithium and risk of colorectal adenocarcinoma using conditional logistic regression.

Results: Long-term use of lithium was similar among cases (0.22\%) and controls $(0.20 \%)$, yielding an odds ratio of $1.13(95 \%$ confidence interval $(\mathrm{Cl}), 0.89-1.43)$ for colorectal adenocarcinoma. Dose-response, subgroup and other subanalyses returned neutral associations. However, ORs differed for colorectal subsites (proximal colon: 1.01 (95\% Cl, 0.66-1.55; distal colon: 1.52 (95\% $\mathrm{Cl}, 1.05-2.20)$; and rectum: $0.80(95 \% \mathrm{Cl}, 0.50-1.30)$.

Conclusions: Lithium use was not associated with an overall increased risk of colorectal adenocarcinoma. The variation by subsite warrants further investigation.

Lithium is first-line therapy in bipolar affective disorder (Licht, 2012) and as adjuvant therapy in unipolar depression (Bauer et al, 2014; Bschor, 2014). The colonic epithelium is exposed to lithium as $10-20 \%$ of an oral dose is eliminated by faeces (Saran and Russell, 1976; Kersten et al, 1986). Lithium enters the colon epithelium through the $\mathrm{Na}^{+}$channel ENaC (Diamond et al, 1983; Mall et al, 1999) and studies have demonstrated accumulation in the epithelium (Dolman and Edmonds, 1976; Dolman et al, 1976; Diamond et al, 1983).

It is unknown whether lithium induces proliferative changes in the colon as demonstrated in kidney and endometrial tissue (Christensen et al, 2006; Polotsky et al, 2009). Tumour cells from mice with adenomatous polyposis coli mutant-multiple intestinal neoplasia (Min) express increased $\mathrm{ENaC}$ activity (Ousingsawat et al, 2008), and when treated with lithium these mice develop larger tumours (Gould et al, 2003). In addition, lithium inhibits glycogen synthase kinase- 3 beta (GSK-3 $\beta$ ) in humans (Klein and Melton, 1996); an important part of the Wnt-signalling pathway that possesses anti-carcinogenic properties in many tissues, including the colorectum.

As colorectal cancer is common and has many established risk factors, any carcinogenic effect of lithium might remain unrecognised due to the low prevalence of lithium use. Identifying or disproving risks suggested to be associated with lithium use is instrumental in ensuring rational therapy with this drug. Recently, we examined the association between lithium use and risk of renal

*Correspondence: A Pottegård; E-mail: apottegaard@health.sdu.dk

Received 22 September 2015; revised 18 December 2015; accepted 26 December 2015; published online 11 February 2016

(c) 2016 Cancer Research UK. All rights reserved 0007-0920/16 
cancer based on a recent study showing a strong correlation between the two (Zaidan et al, 2014), finding a reassuring null association (Pottegård et al, 2015). This prompted us to examine the association between long-term use of lithium and risk of colorectal adenocarcinoma in an additional study using the Danish high-quality registry data.

\section{MATERIALS AND METHODS}

The study was a nationwide case-control study. We compared use of lithium among persons with colorectal cancer (cases) to that of cancer-free persons (controls) and estimated odds ratios (ORs) for colorectal adenocarcinoma associated with long-term use of lithium.

Data sources. We used the Danish Cancer Registry (Storm et al, 1997; Gjerstorff, 2011), the National Prescription Registry (Kildemoes et al, 2011), the National Patient Register (Lynge et al, 2011), registers in Statistics Denmark on educational level (Jensen and Rasmussen, 2011) and the Civil Registration System (Pedersen, 2011). Further details of the nationwide data sources, including codes and definitions are provided in the Supplementary Materials I-II.

All Danish citizens receive free tax-supported health care administered by the national health authorities, allowing population-based register linkage studies covering all inhabitants. Data were linked by the personal identification number assigned to all Danish residents (Pedersen, 2011).

Cases and controls. From the Danish Cancer Registry, we identified all patients (cases) in Denmark with a first time diagnosis of colorectal cancer between 2000 and 2012. We restricted the case population to histologically verified adenocarcinoma. The date of cancer diagnosis was defined as the index date. Exclusion criteria were age outside 18-85 years at index date and any residency outside Denmark within 10 years prior to index date. We further excluded cases with previous cancer (except nonmelanoma skin cancer) as well as subjects with inflammatory bowel disease, hereditary non-polyposis colon cancer or familial adenomatous polyposis.

Controls were selected by risk set sampling, applying the same exclusion criteria as for cases. For each case, we selected 10 cancer-free population controls of same gender and birth year. Index date for controls was identical to that of the corresponding case. Subjects were eligible for multiple control selection before they became cases. Thereby, the ORs provide unbiased estimates of the corresponding incidence rate ratios in the underlying source population.

Exposure definition. Ever use of lithium was defined as having filled two or more prescriptions (ATC code, N05AN01 (WHO Collaborating Centre for Drug Statistics Methodology)) of lithium prior to the index date. Long-term use of lithium was defined as cumulative treatment for $\geqslant 5$ years.

The duration of each lithium prescription was defined as 90 days, that is, we considered the exposure period of one prescription to last 90 days after the date of purchase. In all analyses, we disregarded prescriptions redeemed within 1 year prior to the index date. This was done to reduce the possibility of reverse causation (Jørgensen et al; Csizmadl et al, 2007), and the improbability that very recent exposure would be associated with cancer development (Burstein and Schwartz, 2008).

Main analysis. We used multivariable conditional logistic regression to estimate ORs for colorectal cancer associated with longterm use of lithium, adjusting for potential confounders. In all analyses, non-use (less than two prescriptions) of lithium was the reference group.

Potential confounders included (i) use of aspirin, non-steroidal anti-inflammatory drugs, statins, antidepressants and hormone replacement therapy; (ii) history of type 2 diabetes, chronic obstructive pulmonary disease and alcohol-related disease; and (iii) highest achieved education (as a crude measure of socioeconomic status). Details are presented in the Supplementary Material II. We disregarded the year before the index date for all covariates.

Pre-planned sub-analyses and sensitivity analyses. First, to explore the dose-response relationship between lithium use and colorectal cancer risk, we defined exposure according to various periods of cumulative use of lithium.

Second, we examined associations for colorectal cancer with lithium use stratified by gender, age, year of sampling and histories of diabetes or alcohol abuse.

Third, we estimated ORs for associations between long-term use of lithium and colorectal cancer risk stratified by colorectal subsite, that is, proximal colon, distal colon and rectum.

Finally, we stratified the analyses by localised or non-localised disease.

Other. All analyses were performed using Stata Release 13.1 (StataCorp, College Station, TX, USA). The study was approved by the Danish Data Protection Agency. According to Danish law, studies based solely on register data do not require approval from an ethics review board (Thygesen et al, 2011).

\section{RESULTS}

We identified 51225 colorectal cancer cases. The exclusion criteria left 36248 colorectal adenocarcinoma cases that were matched to 362480 cancer-free population controls (for flowchart, see Supplementary Material III). Baseline characteristics of cases and controls are shown in Table 1.

Table 1. Characteristics of colorectal cancer cases and their matched controls

\begin{tabular}{|l|r|r|}
\hline & $\begin{array}{c}\text { Cases } \\
(\boldsymbol{n}=\mathbf{3 6 2 4 8})\end{array}$ & $\begin{array}{c}\text { Controls } \\
(\boldsymbol{n}=\mathbf{3 6 2 4 8 0})\end{array}$ \\
\hline Age, median (IQR, years) & $70(62-77)$ & $70(62-77)$
\end{tabular}

\section{Gender}

Males

Females

$19868(54.8 \%) \quad 198680(54.8 \%)$

$16380(45.2 \%) \quad 163800(45.2 \%)$

\section{Cancer site}

\section{Colon, proximal}

Colon, distal

Colon, unspecified

Rectum

\begin{tabular}{r|r}
$9771(27.0 \%)$ & NA \\
$11753(32.4 \%)$ & NA \\
$1708(4.7 \%)$ & NA \\
$13016(35.9 \%)$ & NA
\end{tabular}

Use of lithium prior to index date

\begin{tabular}{|l|r|r|}
\hline Non-use & $36089(99.6 \%)$ & $360909(99.6 \%)$ \\
Ever use & $159(0.44 \%)$ & $1571(0.43 \%)$ \\
Long-term use ( $\geqslant 5$ years) & $78(0.22 \%)$ & $734(0.20 \%)$
\end{tabular}

Long-term use ( $\geqslant 5$ years)

\section{Drugs}

Aspirin

NSAID

Statins

Antidepressants

Hormone replacement therapy

$734(0.20 \%)$

\section{Diagnoses}

Diabetes, type 2

COPD

Alcohol-related disease

$9146(25.2 \%)$

$17350(47.9 \%)$

91517 (25.2\%)

7077 (19.5\%)

$179995(49.7 \%)$

$5794(16.0 \%)$

$69082(19.1 \%)$

$6238(17.2 \%)$

$61925(17.1 \%)$

$65106(18.0 \%)$

Highest achieved education

Medium (11-13 years)

Long (>13 years)

$3353(9.3 \%)$

$2728(7.5 \%)$

$2308(6.4 \%)$

$29131(8.0 \%)$

24255 (6.7\%)

$19586(5.4 \%)$

Abbreviations: $I O R=$ inter-quartile range; $N A=$ not applicable; NSAID = non-steroidat anti-

inflammatory drugs. 
Overall, $78(0.22 \%)$ of cases had used lithium for $\geqslant 5$ years compared with $734(0.20 \%)$ among controls. This yielded an adjusted OR of 1.13 (95\% confidence interval (CI) 0.89-1.43) for colorectal adenocarcinoma associated with long-term use of lithium (Table 2).

Analyses defining lithium use according to duration of use yielded ORs close to unity (Table 2). Likewise, analyses stratified by age, gender or selected morbidity revealed no specific patterns in the ORs. In contrast, we found substantial risk variation for colorectal subsites, with ORs for proximal colon, distal colon and rectum of 1.01 (95\% CI $0.66-1.55), 1.52$ (95\% CI 1.05-2.20) and 0.80 (95\% CI $0.50-1.30)$, respectively (Table 3 ). We also observed variation in ORs for localised or non-localised cancer (1.44 (95\% CI 1.01-2.04) vs 1.06 (95\% CI 0.75-1.49)).

Post hoc analyses of the anatomical distribution of the colorectal tumours confirmed a slightly skewed distribution towards those of the distal colon among long-term users of lithium (Supplementary Material IV). When restricting analyses to this sub-set of cases, we observed a suggestive dose-response pattern, however, the

\section{Table 2. Association between lithium use and risk of}

colorectal adenocarcinoma, specified by pattern of use within the entire exposure period, excluding the last year prior to the index date

\begin{tabular}{|c|c|c|c|c|}
\hline $\begin{array}{l}\text { Exposure } \\
\text { group }\end{array}$ & Cases & Controls & Crude OR ${ }^{a}$ & Adjusted OR \\
\hline Non-use & 36089 & 360909 & 1.00 (ref.) & 1.00 (ref.) \\
\hline Ever use & 159 & 1571 & $1.01(0.86-1.19)$ & $1.08(0.92-1.28)$ \\
\hline $\begin{array}{l}\text { Long-term use } \\
(\geqslant 5 \text { years) }\end{array}$ & 78 & 734 & $1.06(0.84-1.34)$ & $1.13(0.89-1.43)$ \\
\hline \multicolumn{5}{|c|}{ Duration of use } \\
\hline$<1$ year & 21 & 277 & $0.76(0.49-1.18)$ & $0.82(0.53-1.28)$ \\
\hline $1-4.99$ years & 60 & 560 & $1.07(0.82-1.40)$ & $1.15(0.88-1.50)$ \\
\hline $5-9.99$ years & 50 & 506 & $0.99(0.74-1.33)$ & $1.06(0.79-1.41)$ \\
\hline$\geqslant 10$ years & 28 & 228 & $1.22(0.83-1.81)$ & $1.29(0.87-1.91)$ \\
\hline \multicolumn{5}{|c|}{$\begin{array}{l}\text { Abbreviation: OR=odds ratio. } \\
\text { a Adjusted for age, calendar time and sex (by matched design). } \\
\text { b }_{\text {Fully adjusted model, see section 'Main analysis'. }}\end{array}$} \\
\hline
\end{tabular}

statistical precision of the individual point estimates was limited (Supplementary Material V). Last, we evaluated the influence of timing of lithium use by stratifying the results for long-term use into initiation of use (defined as first prescription) $<10$ years or $\geqslant 10$ years, respectively, prior to the index date $(<10$ years: OR 1.33 , 95\% CI $0.94-1.90$; $\geqslant 10$ years: OR 0.98 , 95\% CI $0.72-1.35$ ).

\section{DISCUSSION}

In our nationwide case-control study, we found no association between long-term use of lithium and overall risk of colorectal adenocarcinoma. Findings were consistent between patient subgroups and when applying different definitions of lithium use. In analyses stratified by colorectal subsite, the associations deviated substantially, including a statistically significant increased OR for distal colon cancer associated with long-term lithium use.

The main strength of our study is the use of nationwide, comprehensive, high-quality registry data on drug use, cancer outcomes and potential confounders. The weakness of the study is the lack of data on life-style habits, including smoking, obesity and alcohol consumption. Patients with psychiatric diseases have on average higher consumption of tobacco and alcohol than the general population (Lasser et al, 2000; Heffner et al, 2011; McDonald and Meyer, 2011), and both smoking and alcohol are known to induce colorectal cancer (Baan et al, 2007; Secretan et al, 2009). This might have biased our risk estimates slightly upwards. Last, adjustment for the underlying psychiatric indication (i.e., bipolar disorder, severe depression or other) were not feasible due to the possibility of introducing colinearity (as lithium use is closely correlated with the main diagnosis of BPD), lack of information on indications in the Prescription Registry and questionable proxies in the Patient Registry for the relevant conditions.

An unexpected observation was the risk variation by colorectal subsite. Differences in risk estimates between proximal and distal colon tumours have been reported for other drugs (Elsaleh et al, 2000). This is compatible with the different embryological origins and physiology of proximal and distal tumours (Iacopetta, 2002) as well as with differences in molecular and genetic characteristics

Table 3. Associations between long-term use ( $\geqslant 5$ years) of lithium and risk of colorectal adenocarcinoma, stratified by patient subgroups, subsite and stage

\begin{tabular}{|c|c|c|c|c|}
\hline Subgroup & $\begin{array}{l}\text { Cases exposed/ } \\
\text { unexposed }\end{array}$ & $\begin{array}{l}\text { Controls exposed/ } \\
\text { unexposed }\end{array}$ & Crude $\mathrm{OR}^{\mathrm{a}}$ & Adjusted $\mathrm{OR}^{\mathrm{b}}$ \\
\hline \multicolumn{5}{|l|}{ Gender } \\
\hline Males & $28 / 19805$ & $319 / 198001$ & $0.88(0.60-1.29)$ & $0.92(0.62-1.35)$ \\
\hline \multicolumn{5}{|l|}{ Age } \\
\hline$<50$ years & $0 / 1675$ & $16 / 16748$ & - & - \\
\hline $50-69$ years & $38 / 15987$ & $343 / 159905$ & $1.11(0.79-1.55)$ & $1.15(0.82-1.61)$ \\
\hline \multicolumn{5}{|l|}{ Topography } \\
\hline Colon, proximal & $23 / 9725$ & $233 / 97258$ & $0.99(0.64-1.51)$ & $1.01(0.66-1.55)$ \\
\hline Colon, distal & $32 / 11699$ & $228 / 117024$ & $1.41(0.97-2.04)$ & $1.52(1.05-2.20)$ \\
\hline Colon, unspecified & $5 / 1701$ & 27/17016 & $1.85(0.71-4.81)$ & $1.98(0.76-5.16)$ \\
\hline Rectum & $18 / 12964$ & $246 / 129611$ & $0.73(0.45-1.18)$ & $0.80(0.50-1.30)$ \\
\hline \multicolumn{5}{|l|}{ Stage } \\
\hline No history of type 2 diabetes & $71 / 32748$ & $677 / 331896$ & $1.07(0.84-1.37)$ & $1.14(0.89-1.46)$ \\
\hline No history of alcohol abuse & $73 / 33800$ & $636 / 341563$ & $1.15(0.90-1.47)$ & $1.24(0.97-1.59)$ \\
\hline \multicolumn{5}{|c|}{ 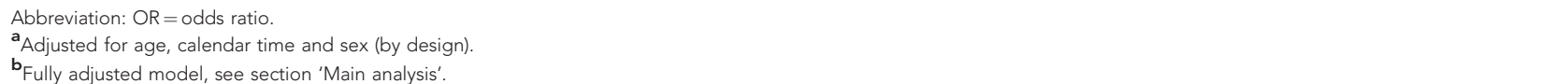 } \\
\hline
\end{tabular}


of the two segments (Iacopetta, 2002; Birkenkamp-Demtroder et al, 2005; Leopoldo et al, 2008). In the present context, $\mathrm{ENaC}$ displays a significant gradient of expression and activity towards distal colon in rodents (Epple et al, 2000; Greig et al, 2002). Whether a similar gradient is present in humans is unknown. Thus, we cannot exclude that the different risk estimates according to colorectal subsite represent true effects. However, the fact that the risk estimates did not increase or decrease uniformly from the proximal segment of colon to rectum also indicates that chance is a likely explanation.

The associations between long-term lithium and colorectal cancer risk also varied with gender, with women exhibiting higher risk estimates than men. A similar gender difference was found in a previous study, showing increased colon cancer mortality among women, but not men, with bipolar disorder (Crump et al, 2013). Last, we found a higher risk estimate for localised than for advanced colorectal cancer, which might result from increased medical surveillance among lithium users. These patients may have a lower threshold for health care contact and thereby may undergo earlier or more intensive diagnostic work-up compared with nonusers of lithium. This might explain our observation of the highest risk estimates for localised disease, and the notion is also compatible with the higher risk estimate observed for distal colon cancer, as proximal colorectal cancers have been shown to present later than distal cancers (Hansen et al, 2015).

In conclusion, use of lithium was not associated with an overall increase in the risk of colorectal adenocarcinoma. The observed association between long-term lithium use and risk of distal colon cancer may warrant further investigation.

\section{ACKNOWLEDGEMENTS}

Sidsel Arnspang Pedersen and Lotte Rasmussen are acknowledged for valuable comments on the manuscript. Morten Olesen is acknowledged for data management support. AP is funded by the Danish Council for Independent Research (grant 4004-00234B).

\section{CONFLICT OF INTEREST}

The authors declare no conflict of interest.

\section{REFERENCES}

Baan R, Straif K, Grosse Y, Secretan B, Ghissassi F, El, Bouvard V, Altieri A, Cogliano V. WHO International Agency for Research on Cancer Monograph Working Group (2007) Carcinogenicity of alcoholic beverages. Lancet Oncol 8: 292-293.

Bauer M, Adli M, Ricken R, Severus E, Pilhatsch M (2014) Role of lithium augmentation in the management of major depressive disorder. CNS Drugs 28: 331-342.

Birkenkamp-Demtroder K, Olesen SH, Sørensen FB, Laurberg S, Laiho P, Aaltonen LA, Orntoft TF (2005) Differential gene expression in colon cancer of the caecum versus the sigmoid and rectosigmoid. Gut 54: 374-384.

Bschor T (2014) Lithium in the treatment of major depressive disorder. Drugs 74: $855-862$.

Burstein HJ, Schwartz RS (2008) Molecular origins of cancer. N Engl J Med 358: 527.

Christensen BM, Kim Y-H, Kwon T-H, Nielsen S (2006) Lithium treatment induces a marked proliferation of primarily principal cells in rat kidney inner medullary collecting duct. Am J Physiol Renal Physiol 291: F39-F48.

Crump C, Sundquist K, Winkleby MA, Sundquist J (2013) Comorbidities and mortality in bipolar disorder: a Swedish national cohort study. JAMA Psychiatry 70: 931-939.

Csizmadl I, Collet J-P, Boivin J (2007) Bias and confounding in pharmacoepidemiology. In: Pharmacoepidemiology, Strom BL (ed) 4th edn. John Wiley \& Sons: Chichester, UK.
Diamond JM, Ehrlich BE, Morawski SG, Santa Ana CA, Fordtran JS (1983) Lithium absorption in tight and leaky segments of intestine. J Membr Biol 72: 153-159.

Dolman D, Edmonds CJ, Salas-Coll C (1976) Effect of aldosterone on lithium permeability of rat colon mucosa. J Endocrinol 70: 135-140.

Dolman DE, Edmonds CJ (1976) Lithium transport by the colon of normal and sodium-depleted rats. J Physiol 259: 759-770.

Elsaleh H, Joseph D, Grieu F, Zeps N, Spry N, Iacopetta B (2000) Association of tumour site and sex with survival benefit from adjuvant chemotherapy in colorectal cancer. Lancet Lond Engl 355: 1745-1750.

Epple HJ, Amasheh S, Mankertz J, Goltz M, Schulzke JD, Fromm M (2000) Early aldosterone effect in distal colon by transcriptional regulation of ENaC subunits. Am J Physiol Gastrointest Liver Physiol 278: G718-G724.

Gjerstorff ML (2011) The Danish Cancer Registry. Scand J Public Health 39: $42-45$.

Gould TD, Gray NA, Manji HK (2003) Effects of a glycogen synthase kinase-3 inhibitor, lithium, in adenomatous polyposis coli mutant mice. Pharmacol Res Off J Ital Pharmacol Soc 48: 49-53.

Greig ER, Baker EH, Mathialahan T, Boot-Handford RP, Sandle GI (2002) Segmental variability of $\mathrm{ENaC}$ subunit expression in rat colon during dietary sodium depletion. Pflüg Arch Eur J Physiol 444: 476-483.

Hansen PL, Hjertholm P, Vedsted P (2015) Increased diagnostic activity in general practice during the year preceding colorectal cancer diagnosis. Int $J$ Cancer 137: 615-624.

Heffner JL, Strawn JR, DelBello MP, Strakowski SM, Anthenelli RM (2011) The co-occurrence of cigarette smoking and bipolar disorder: phenomenology and treatment considerations. Bipolar Disord 13: 439-453.

Iacopetta B (2002) Are there two sides to colorectal cancer? Int J Cancer 101: 403-408.

Jensen VM, Rasmussen AW (2011) Danish Education Registers. Scand J Public Health 39: 91-94.

Jørgensen T, Herrstedt J, Friis S, Hallas J (2012) Danish cancer patients during 1996 to 2006. J Geriatr Oncol 3: 33-40.

Kersten L, Fleck C, Bräunlich H (1986) Evidence for an intestinal lithium excretion in rats. Exp Pathol 29: 55-63.

Kildemoes HW, Sørensen HT, Hallas J (2011) The Danish National Prescription Registry. Scand J Public Health 39: 38-41.

Klein PS, Melton DA (1996) A molecular mechanism for the effect of lithium on development. Proc Natl Acad Sci USA 93: 8455-8459.

Lasser K, Boyd JW, Woolhandler S, Himmelstein DU, McCormick D, Bor DH (2000) Smoking and mental illness: a population-based prevalence study. JAMA 284: 2606-2610.

Leopoldo S, Lorena B, Cinzia A, Gabriella DC, Angela Luciana B, Renato C, Antonio M, Carlo S, Cristina P, Stefano C, Maurizio T, Luigi R, Cesare B (2008) Two subtypes of mucinous adenocarcinoma of the colorectum: clinicopathological and genetic features. Ann Surg Oncol 15: 1429-1439.

Licht RW (2012) Lithium: still a major option in the management of bipolar disorder. CNS Neurosci Ther 18: 219-226.

Lynge E, Sandegaard JL, Rebolj M (2011) The Danish National Patient Register. Scand J Public Health 39: 30-33.

Mall M, Bleich M, Kuehr J, Brandis M, Greger R, Kunzelmann K (1999) CFTR-mediated inhibition of epithelial $\mathrm{Na}+$ conductance in human colon is defective in cystic fibrosis. Am J Physiol 277: G709-G716.

McDonald JL, Meyer TD (2011) Self-report reasons for alcohol use in bipolar disorders: why drink despite the potential risks? Clin Psychol Psychother 18: 418-425.

Ousingsawat J, Spitzner M, Schreiber R, Kunzelmann K (2008) Upregulation of colonic ion channels in APC $(\mathrm{Min} /+)$ mice. Pflüg Arch Eur J Physiol 456: $847-855$.

Pedersen CB (2011) The Danish Civil Registration System. Scand J Public Health 39: 22-25.

Polotsky AJ, Zhu L, Santoro N, Pollard JW (2009) Lithium chloride treatment induces epithelial cell proliferation in xenografted human endometrium. Hum Reprod Oxf Engl 24: 1960-1967.

Pottegård A, Hallas J, Jensen BL, Madsen K, Friis S (2015) Long-term lithium use and risk of renal and upper urinary tract cancers. J Am Soc Nephrol 27(1): 249-255.

Saran BM, Russell GF (1976) The effects of administering lithium carbonate on the balance of $\mathrm{Na}, \mathrm{K}$ and water in manic-depressive patients. Psychol Med 6: 381-392.

Secretan B, Straif K, Baan R, Grosse Y, Ghissassi F, El, Bouvard V, BenbrahimTallaa L, Guha N, Freeman C, Galichet L, Cogliano V. WHO International 
Agency for Research on Cancer Monograph Working Group (2009) A review of human carcinogens-Part E: tobacco, areca nut, alcohol, coal smoke, and salted fish. Lancet Oncol 10: 1033-1034.

Storm HH, Michelsen EV, Clemmensen IH, Pihl J (1997) The Danish Cancer Registry-history, content, quality and use. Dan Med Bull 44: 535-539.

Thygesen LC, Daasnes C, Thaulow I, Brønnum-Hansen H (2011) Introduction to Danish (nationwide) registers on health and social issues: structure, access, legislation, and archiving. Scand J Public Health 39: $12-16$.

WHO Collaborating Centre for Drug Statistics Methodology. Guidelines for ATC classification and DDD assignment 2015. Oslo, Denmark.

Zaidan M, Stucker F, Stengel B, Vasiliu V, Hummel A, Landais P, Boffa J-J, Ronco P, Grünfeld J-P, Servais A (2014) Increased risk of solid renal tumors in lithium-treated patients. Kidney Int 86: 184-190.

Supplementary Information accompanies this paper on British Journal of Cancer website (http://www.nature.com/bjc) 